\title{
Carcass characteristics and meat quality of purebred Pakchong 5 and crossbred pigs sired by Pakchong 5 or Duroc boar
}

\author{
Rachakris Lertpatarakomol ${ }^{1,2, *}$, Chanporn Chaosap ${ }^{3}, K_{\text {Kamon Chaweewan }}^{4}$, \\ Ronachai Sitthigripong ${ }^{1}$, and Rutcharin Limsupavanich ${ }^{1, *}$
}

\author{
* Corresponding Authors: \\ Rachakris Lertpatarakomol \\ Tel: +66-8-9127-2611, Fax: +66-2-988-4040, \\ E-mail: rachakris@gmail.com \\ Rutcharin Limsupavanich \\ Tel: +66-8-4384-9991, Fax: +66-2-329-8519, \\ E-mail: rlimsupa@gmail.com
}

'Department of Animal Production Technology and Fisheries, Faculty of Agricultural Technology, King

Mongkut's Institute of Technology Ladkrabang,

Bangkok 10520, Thailand

2 Faculty of Veterinary Medicine, Mahanakorn

University of Technology, Bangkok 10530, Thailand

${ }^{3}$ Department of Agricultural Education, Faculty of

Industrial Education and Technology, King Mongkut's

Institute of Technology Ladkrabang, Bangkok 10520,

Thailand

${ }^{4}$ Bureau of Animal Husbandry and Genetic

Improvement, Department of Livestock Development,

Bangkok, 10400, Thailand

ORCID

Rachakris Lertpatarakomol

https://orcid.org/0000-0002-0805-1764

Chanporn Chaosap

https://orcid.org/0000-0002-3816-1884

Kamon Chaweewan

https://orcid.org/0000-0001-5064-1285

Ronachai Sitthigripong

https://orcid.org/0000-0002-8671-0606

Rutcharin Limsupavanich

https://orcid.org/0000-0002-3533-6562

Submitted Apr 7, 2018; Revised Jul 12, 2018; Accepted Aug 28, 2018

\begin{abstract}
Objective: This study investigated carcass characteristics and meat quality of purebred Pakchong 5, crossbred pigs sired by Pakchong 5, and crossbred pigs sired by Duroc.

Methods: Forty-eight pigs (average body weight of $22.25 \mathrm{~kg}$ ) were composed of three groups as purebred Pakchong 5 (PP), Large WhitexLandrace pigs sired by Pakchong 5 (LWLRP), and Large WhitexLandrace pigs sired by Duroc (LWLRD). Each group consisted of eight gilts and eight barrows. At 109-day-raising period, pigs were slaughtered, and carcass characteristics were evaluated. Longissimus thoracis (LT) muscles from left side of carcasses were evaluated for meat quality and chemical composition. Data were analyzed using general linear model procedure, where group, sex, and their interaction were included in the model.

Results: The PP had greater carcass, total lean, and ham percentages than crossbred pigs ( $\mathrm{p}<$ $0.05)$. LWLRP had thicker backfat and more carcass fat percentage than LWLRD $(\mathrm{p}<0.05)$. There were no differences ( $\mathrm{p}>0.05$ ) on cutting percentages from tender loin, loin, boston butt, and picnic shoulder among groups. The PP and LWLRP had larger loin eye area (LEA) than LWLRD $(p<0.05)$. Gilts had more loin percentage and lower $\mathrm{L}^{*}$ value than barrows $(\mathrm{p}<0.05)$. No meat color parameters $\left(L^{*}, a^{*}\right.$, and $\left.b^{*}\right)$ were affected by groups $(p>0.05)$. PP and LWLRP had larger muscle fiber diameters than LWLRD $(\mathrm{p}<0.05)$. However, water holding capacity, Warner-Bratzler shear force values, and chemical composition of LT were not affected by group or $\operatorname{sex}(\mathrm{p}>0.05)$.

Conclusion: Pakchong 5 purebred has good carcass and lean percentages. Compared to Duroc crossbred pigs, Pakchong 5 crossbreds have similar carcass and lean percentages, larger LEA, and slightly more carcass fat, with comparable meat quality and chemical composition. Pakchong 5 boars are more affordable for very small- to medium-scale pig producers.
\end{abstract}

Keywords: Pakchong 5; Terminal Boar; Crossbred Pig; Carcass Characteristic; Meat Quality; Duroc

\section{INTRODUCTION}

Pork is the most important red meat consumed in Thailand with an increased consumption of about $4.18 \%$ in 2016 compared to that in 2015 [1]. Similar to other countries, an increasing in lean to fat ratio of pig carcasses has been set as one of the major goals in Thai swine production industry, while meat quality becomes more important. Pig breed particularly is an important factor for improving pork economical traits [2,3], especially using terminal sire or prominent boar $[4,5]$. Three-line crossbred pigs have intermediate values of parents for carcass and meat quality traits $[5,6]$. However, pork quality variation among different genders has been reported $[2,4,7,8]$.

In Thailand, Duroc breed is widely used as terminal boar to produce three-line crossbred pigs (Large White $\times$ Landrace $\times$ Duroc). The synthetic commercial breeds, offered by large-scale 
pork producers, have become popular terminal boars for the swine production industry [9]. Although 95\% of total swine production is for local consumption and majorly supplied by large-scale pork producers [10]. It has been reported in 2015 that the major pork producers, approximately $94.98 \%$, are very small-scale. In addition, $3.68 \%$ are small-scale and $1.20 \%$ are medium-scale. The prominent boars from commercial breeders are usually unaffordable for the very small- to medium-scale producers. To support these small holders, pig breeds with improved carcass and meat quality traits should be developed for use as terminal sires. Furthermore, these animals should be made economically available to small producers, especially to those in provincial areas.

Pakchong 5 pig has been developed by the Department of Livestock Development of Thailand. It is a synthetic terminal boar established from a genetic combination of $62.5 \%$ Duroc and $37.5 \%$ Pietrain breeds. It was derived from the inter se mating and selected for important economical traits for five generations. These traits include average daily gain of more than $850 \mathrm{~g} / \mathrm{d}$, feed conversion ratio of less than 2.50 , backfat thickness of less than $1.0 \mathrm{~cm}$, and loin eye area (LEA) of larger than $37 \mathrm{~cm}^{2}$ [9]. It was proposed to be used as a terminal boar for producing fast growing and lean fattening pigs for very small- to medium-scale pork holders [9]. Its carcass and meat quality, however, have not been examined. As a result, we investigated carcass characteristics and meat quality of different fattening pigs including purebred Pakchong 5 , crossbred pigs sired by Pakchong 5 boar, and crossbred pigs sired by Duroc boar as well as to compare gender effect.

\section{MATERIALS AND METHODS}

Animal care and use

The experimental procedure on animal care and use was approved by the Institutional Animal Care and Use Committee of King Mongkut's Institute of Technology Ladkrabang (AGRIKMITL002/2015).

\section{Animals and sampling}

Forty-eight pigs were included in this study. They were separated into three experimental groups consisting of purebred Pakchong 5 (PP), Large White $\times$ Landrace pigs sired by Pakchong 5 boar (LWLRP), and Large WhitexLandrace pigs sired by Duroc boar (LWLRD). Each group included 16 pigs, which were eight gilts and eight barrows. All pigs were raised in the same fattening pig farm in Nakorn Ratchasima, Thailand. Sixteen animals of each treatment were allocated into a $4 \times 4-\mathrm{m}^{2}$ pen. The pens were constructed with $30-\mathrm{cm}$-high concrete walls topped with metal railings for well ventilation and nonslip cement flooring. Pigs had access to a shallow pond, which was built inside at the end of each pen, to allow the pigs to clean their bodies and reduce body temperature. Water in the shal- low ponds was released into a waste water pond every 3 to 5 days for agricultural utilization or biogas production. Each pen was also equipped with automatic feeders and water dispensers. Feedings were given to the animals ad libitum with 2 basal diet formulas for growers (20 to $50 \mathrm{~kg}$ body weight [BW]) and finishers (50 to $110 \mathrm{~kg} \mathrm{BW)} \mathrm{as} \mathrm{presented} \mathrm{in} \mathrm{Table}$ 1. Raising period was started when the pigs had average BW of $22.25 \pm 3.27 \mathrm{~kg}$ and finished at 109 days. No statistical analysis was performed to compare growing characteristics and feed intakes of the experimental treatments. For 109 days of raising period, accumulate feed consumptions of PP, LWLRP, and LWLRD were $297.50,286.56$, and $286.56 \mathrm{~kg}$, respectively. At the end of the experiment, sixteen pigs, with approximate live weight of $100 \mathrm{~kg}$, from each group were fasted for $12 \mathrm{~h}$ and transported approximately $15 \mathrm{~km}$ or within $30 \mathrm{~min}$ driving to the abattoir. Animals were rested for $2 \mathrm{~h}$ before slaughtering with free access to water. Each animal was weighed prior to being electrically stunned, bled, scalded, de-haired, eviscerated, and split to obtain carcass data. For meat quality evaluation, Longissimus thoracis (LT) muscles from the right side of all carcasses were collected and transported $\left(3^{\circ} \mathrm{C} \pm 2^{\circ} \mathrm{C}\right)$ to meat science and technology laboratory, Faculty of Agricultural Technology, King Mongkut's Institute of Technology Ladkrabang (KMITL), Thailand and kept in a walk-in chiller $\left(2^{\circ} \mathrm{C} \pm 2^{\circ} \mathrm{C}\right)$.

\section{Carcass characteristics}

Carcass characteristics were determined from the left side of all carcasses based on hot carcass weight. Carcass length was measured from the cranial edge of the first rib to cranial tip of the aitch bone. Average backfat thickness was measured from the first rib, last rib, and last lumbar. The LEA was de-

Table 1. Formula of basal diets

\begin{tabular}{lcc}
\hline Ingredients (\%) & $\begin{array}{c}\text { Grower } \\
(\mathbf{2 0}-\mathbf{5 0 ~} \mathbf{~ g W})\end{array}$ & $\begin{array}{c}\text { Finisher } \\
\mathbf{( 5 0 - 1 1 0 ~} \mathbf{~ g ~ B W})\end{array}$ \\
\hline Broken rice & 51.70 & 54.86 \\
Rice bran & 15.00 & 19.95 \\
Soybean meal & 21.00 & 15.96 \\
Fish meal & 5.00 & 3.99 \\
Di-calcium phosphate & 4.00 & 3.99 \\
Vegetable oil & 2.00 & 0.00 \\
Salt & 0.50 & 0.50 \\
Antibiotic & 0.30 & 0.25 \\
Premix & 0.50 & 0.50 \\
Calculated analysis & & \\
$\quad$ ME (kcal/kg) & 3,214 & 3,156 \\
Crude protein (\%) & 17.98 & 16.08 \\
\hline
\end{tabular}

BW, body weight; $\mathrm{ME}$, metabolizable energy.

1) Supplied per kg diet: Vitamin A 8,000,000 IU; Vitamin D 1,500,000 IU; Vitamin E 40,000 ppm; Vitamin K 1,500 ppm; Thiamin 1,000 ppm; Riboflavin 4,000 ppm; Vitamin $B_{12} 20$ ppb; Pyridoxine 2,000 ppm; Niacin 20,000 ppm; Biotin 30 ppm; Folic acid 600 ppm; Se 250 mg; I 200 mg; Fe 60,000 mg; Mn 25,000 mg; Zn $60,000 \mathrm{mg}$; Cu 15,000 mg. 
termined by tracing on a transparent plastic sheet placed on the cut surface of Longissimus muscle between the 10th-11th ribs. The traced LEA was measured using a leaf area meter (LI-3100C, LI-COR Inc. Lincoln, NE, USA). At 45 min postmortem, Longissimus muscle $\mathrm{pH}$ was directly measured on the loin eye surface on the 10th rib using a $\mathrm{pH}$ meter equipped with a spear tip glass electrode (Model SG2 - ELK Seven Go, Mettler-Toledo International Inc., Giessen, Germany). Tender loin and primal cuts, including loin, boston shoulder, picnic shoulder, ham, and belly, were separated from each carcass and weighed. Total lean percentage was calculated from the weights of tender loin and four primal cuts.

\section{Meat quality}

At $24 \mathrm{~h}$ postmortem, LT muscle $\mathrm{pH}$ was measured using a $\mathrm{pH}$ meter equipped with a spear tip glass electrode (Model SG2 - ELK Seven Go, Mettler-Toledo International Inc., Germany). Commission Internationale de I'Eclairage (CIE) $\mathrm{L}^{*}, \mathrm{a}^{*}$ and $\mathrm{b}^{*}$ color values were determined on the cut surfaces of $3-\mathrm{cm}$ thick LT slices, after allowing to bloom for $45 \mathrm{~min}$ at $25^{\circ} \mathrm{C} \pm 2^{\circ} \mathrm{C}$, using a portable spectrophotometer (MiniScan EZ, Illuminant D65, $10^{\circ}$ standard observer, 2.5-cm-aperture, Hunter Associates Laboratory Inc., Reston, VA, USA). Water holding capacity (WHC) was determined by the method in the literature $[5,11]$. For drip loss, two pieces of 1.5 -cm-thick slices obtained from each LT muscle were weighed, hanged in a closed high-density polyethylene bag and stored at $2^{\circ} \mathrm{C} \pm 2^{\circ} \mathrm{C}$ for $48 \mathrm{~h}$. Care was taken to protect meat from touching the bag. Drip loss percentage was calculated by measuring weight loss as a percentage of original meat weight. For cooking loss, two pieces of 3-cmthick slices obtained from each LT muscle were weighed and placed into high-density polyethylene bag. Care was taken to remove air inside the bag as much as possible before heat sealing the package. The sealed package was then placed into a water bath set at $80^{\circ} \mathrm{C}$ for $40 \mathrm{~min}$ or until core temperature of meat sample reached $70^{\circ} \mathrm{C}$. Samples were cooled down to room temperature before weighing and calculating sample weight difference before and after cooking as a percentage of weight before cooking. Warner-Bratzler shear force (WBSF) values were derived from using ten $1 \times 1 \times 3 \mathrm{~cm}^{3}$ cooked pieces of each cooking loss sample. WBSF was measured using an Instron Universal Testing Machine (model 2519-104, Instron, Norwood, MA, USA) equipped with a $50 \mathrm{~kg}$ load cell using 200 $\mathrm{mm} / \mathrm{min}$ crosshead speed [11]. Muscle fiber diameter was determined from 200 muscle fibers of $100 \mathrm{~g}$ samples by using $4 \times$ compound microscope equipped with Dino-Eye eyepiece camera to capture images and subsequently evaluated with Dino Capture version 2.0 software (AnMo Electronics Corporation, New Taipei City, Taiwan) [12]. Sarcomere length data were determined from two $2 \times 2 \times 2-\mathrm{cm}^{3}$ cubes of muscle samples according to previous study [13]. Sarcomere length of each muscle sample was calculated from 30 sarcomeres of 30 different muscle fibers. The meat samples were analyzed for dry matter $(\mathrm{DM})$, crude protein $(\mathrm{CP})$, ether extract (EE), and ash by AOAC methods [14]. DM was determined by drying the samples at $105^{\circ} \mathrm{C}$ in a hot-air oven. $\mathrm{CP}$ and $\mathrm{EE}$ were determined by the Kjeldahl method and Soxhlet extraction method. Ash was determined at $550^{\circ} \mathrm{C}$ overnight in a furnace. The soluble and insoluble collagen contents in muscle were determined according to the method described by Hill [15] with slight modifications. The sample was homogenized with Ringer's solution at $77^{\circ} \mathrm{C}$ for $70 \mathrm{~min}$ and centrifuged for $10 \mathrm{~min}$ at 2,500 g. The supernatant solutions were hydrolyzed in $12 \mathrm{~N} \mathrm{HCl}$ and the sediments were hydrolyzed in $6 \mathrm{~N} \mathrm{HCl}$ for $24 \mathrm{~h}$ at $110^{\circ} \mathrm{C}$. The amount of hydroxyproline was calculated from standard curve of hydroxyproline at the absorbance of $550 \mathrm{~nm}$.

\section{Statistical analysis}

Data were considered as a $3 \times 2$ factorial arrangement in completely randomized design, with 3 groups (PP, LWLRP, and LWLRD) and 2 sexes (gilt and barrow). The general linear model procedure of SPSS version 17.0 [16] was used for analysis of variance to analyze all parameters included the effects of group, sex, and their interaction. Due to the slaughter weight significantly differing between animals, live weight was fitted as a linear covariate for analyzing carcass characteristic traits. Duncan's multiple range test was used to compare differences between mean values at a 5\% level of significance. For the interaction, mean comparisons were performed among the 6 treatment combinations. If the interaction was not significant, mean comparisons were performed only for main effects.

\section{RESULTS AND DISCUSSION}

\section{Carcass characteristics}

Carcass characteristics of Pakchong 5 purebred and the two groups of crossbred pigs are shown in Table 2. No combined effects of group and sex were found on any carcass traits. Therefore, the influences from main effects are presented. At 109-dayraising period, $\mathrm{PP}$ had the lowest live weight compared to the two groups of crossbred pigs $(\mathrm{p}<0.05)$. Crossbred pigs were reported to grow more rapidly than purebred pigs, due to the heterosis effect on crossbreds, which had a genetic variation among breeds of sire and dam [17]. Duroc-sired progeny have been reported to have faster BW gain, whereas Pietrain-sired progeny grew more slowly with less fat accumulation [18]. The slower growth rate characteristic of Pietrain, however, was not observed in LWLRP. By 109-day-raising, LWLRP (105.28 $\mathrm{kg}$ ) was heavier $(\mathrm{p}>0.05)$ than LWLRD $(101.67 \mathrm{~kg})$, although statistically insignificant. There was no difference on hot carcass weight among treatments ( $>00.05)$. The carcass length of LWLRP was like PP, but it tended $(\mathrm{p}=0.08)$ to be slightly shorter than LWLRD $(84.7,84.7$, and $87.7 \mathrm{~cm}$, respectively). PP had greater carcass and total lean percentages than those 
Table 2. Means \pm standard deviation of carcass traits of finished Pakchong 5 pig and crossbred pigs sired by Pakchong 5 or Duroc boar

\begin{tabular}{|c|c|c|c|c|c|c|c|c|}
\hline \multirow{2}{*}{ Items } & \multicolumn{3}{|c|}{ Group $(G)^{1)}$} & \multicolumn{2}{|c|}{$\operatorname{Sex}(S)$} & \multicolumn{3}{|c|}{$\mathrm{p}$-value } \\
\hline & PP & LWLRP & LWLRD & Gilt & Barrow & G & $S$ & $\mathrm{G} \times \mathrm{S}$ \\
\hline Live weight (kg) & $93.56 \pm 6.54^{b}$ & $105.28 \pm 8.47^{\mathrm{a}}$ & $101.67 \pm 7.90^{\mathrm{a}}$ & $98.53 \pm 8.15$ & $101.81 \pm 9.77$ & $<0.01$ & 0.13 & 0.09 \\
\hline Hot carcass weight $(\mathrm{kg})$ & $84.49 \pm 6.01$ & $83.76 \pm 6.87$ & $83.15 \pm 6.83$ & $83.50 \pm 6.69$ & $84.09 \pm 8.10$ & 0.12 & 0.22 & 0.83 \\
\hline Carcass length $(\mathrm{cm})$ & $84.69 \pm 4.90$ & $84.74 \pm 3.44$ & $87.69 \pm 3.70$ & $85.83 \pm 4.93$ & $85.58 \pm 4.38$ & 0.08 & 0.83 & 0.88 \\
\hline Carcass percentage & $79.89 \pm 1.51^{\mathrm{a}}$ & $78.1 \pm 2.14^{b}$ & $78.32 \pm 0.99^{b}$ & $78.62 \pm 1.11$ & $78.93 \pm 2.17$ & 0.01 & 0.51 & 0.74 \\
\hline Backfat thickness (mm) & $19.36 \pm 3.67^{b}$ & $22.27 \pm 5.24^{\mathrm{a}}$ & $18.84 \pm 4.16^{b}$ & $19.32 \pm 3.53$ & $20.99 \pm 5.59$ & 0.03 & 0.14 & 0.95 \\
\hline Total lean percentage $e^{2)}$ & $47.04 \pm 2.38^{a}$ & $44.36 \pm 1.77^{b}$ & $45.03 \pm 1.53^{b}$ & $45.90 \pm 2.36$ & $45.05 \pm 1.99$ & $<0.01$ & 0.15 & 0.46 \\
\hline Total fat percentage & $11.56 \pm 1.97^{b}$ & $12.94 \pm 2.27^{\mathrm{a}}$ & $11.33 \pm 1.09^{b}$ & $11.49 \pm 1.49$ & $12.39 \pm 2.27$ & 0.02 & 0.08 & 0.10 \\
\hline \multicolumn{9}{|l|}{ Cutting percentage } \\
\hline Tender loin & $1.41 \pm 0.14$ & $1.36 \pm 0.17$ & $1.36 \pm 0.13$ & $1.38 \pm 0.14$ & $1.38 \pm 0.16$ & 0.63 & 0.93 & 0.87 \\
\hline Loin & $8.33 \pm 0.68$ & $8.16 \pm 0.86$ & $8.22 \pm 0.73$ & $8.52 \pm 0.74^{x}$ & $7.95 \pm 0.68^{y}$ & 0.83 & 0.01 & 0.62 \\
\hline Boston butt & $4.73 \pm 0.53$ & $4.60 \pm 0.39$ & $4.41 \pm 0.28$ & $4.58 \pm 0.40$ & $4.57 \pm 0.45$ & 0.18 & 0.93 & 0.08 \\
\hline Picnic shoulder & $10.35 \pm 0.85$ & $10.34 \pm 1.11$ & $10.47 \pm 0.88$ & $10.49 \pm 0.95$ & $10.28 \pm 0.93$ & 0.93 & 0.49 & 0.48 \\
\hline Ham & $21.42 \pm 1.37^{\mathrm{a}}$ & $19.37 \pm 1.46^{b}$ & $19.89 \pm 1.07^{b}$ & $20.33 \pm 1.76$ & $20.12 \pm 1.33$ & $<0.01$ & 0.60 & 0.29 \\
\hline Belly & $12.42 \pm 1.14^{b}$ & $13.39 \pm 1.47^{\mathrm{a}}$ & $12.53 \pm 1.07^{b}$ & $12.57 \pm 1.05$ & $12.99 \pm 1.32$ & 0.04 & 0.23 & 0.73 \\
\hline Loin eye area $\left(\mathrm{cm}^{2}\right)$ & $55.12 \pm 9.47^{\mathrm{a}}$ & $53.62 \pm 9.70^{a}$ & $47.21 \pm 7.62^{b}$ & $53.24 \pm 10.55$ & $50.73 \pm 8.35$ & 0.04 & 0.34 & 0.11 \\
\hline
\end{tabular}

1) PP, purebred Pakchong 5; LWLRP, Large White $\times$ Landrace pigs sired by Pakchong 5 boar; LWLRD, Large White $\times$ Landrace pigs sired by Duroc boar.

${ }^{2)}$ Total lean percentage was calculated from tender loin, loin, boston butt, picnic shoulder, and ham.

Means within the same row with different superscript letters $\left({ }^{(a, b}\right)$ under group effect differed at $p<0.05$. Means within the same row with different superscript letters $\left({ }^{x, y}\right)$ under sex effect differed at $p<0.05$.

of the crossbred pigs $(\mathrm{p}<0.05)$, but no difference was found between the two crossbred groups ( $p>0.05)$. These assured the lean characteristic of PP synthetic breed as purposed [9]. On the other hand, LWLRP had slightly thicker backfat and higher total carcass fat percentage than PP and LWLRD $(\mathrm{p}<$ 0.05 ). But there was no difference ( $p>0.05$ ) in both traits between PP and LWLRD. Although it is generally acknowledged that the Duroc breed tends to grow faster and accumulate more fat [18]. The commercial Duroc sire for producing LWLRD in this study might be selected for lean production. But the genetic potential of Duroc in Pakchong 5 sire was selected for growth and lean. In the present study, the same feed formulation was offered to the pigs for the whole finishing period without adjustment. As LWLRP rapidly grew to a certain weight, it could likely accumulate more fat. The average backfat thickness of LWLRP, however, was less than $2.5 \mathrm{~cm}$.

For carcass cutting percentages (Table 2), there were no differences on tender loins, loins, boston butts, and picnic shoulders among groups $(\mathrm{p}>0.05)$. PP had greater $(\mathrm{p}<0.05)$ ham percentage than LWLRP and LWLRD, whereas no difference ( $p>0.05$ ) was found between the two crossbred pigs. It might be due to purebred Pakchong 5 pigs had the genetic potential from the combination of Pietrain breed. In agreement with researchers who indicated that lean meat and ham percentages of Pietrain breed were higher than those of Duroc breed $[19,20]$. Belly percentage of PP and LWLRD was similar ( $p>0.05$ ), but both groups had less belly percentage than LWLRP $(\mathrm{p}<0.05)$. The larger proportion of belly in LWLRP was likely due to slightly more carcass fat accumulation compared to the others. On the other hand, LEA of LWLRP did not differ from $\mathrm{PP}(\mathrm{p}>0.05)$, while both were larger $(p<0.05)$ than that of LWLRD. LEA is generally well correlated to muscle percentage [21]. In contrast to our study, previous research reported that Duroc crossbred (Duroc $\times$ Large White) and Pietrain crossbred (Pietrain $\times$ Large White) had no statistically significant difference in LEA [22]. No gender effect ( $p>0.05$ ) was observed on any carcass traits, with the exception for loin percentage. Gilts appeared to have more $(\mathrm{p}<0.05)$ loin percentage than barrows. Previous report showed that the proportion of trimmed loin was greater for gilts than that from barrows [2].

\section{Meat quality}

No interaction effects of group and sex were observed on meat quality traits ( $p>0.05$, Table 3 ). Therefore, the influences of main effects are presented. The LT muscle $\mathrm{pH}$ was not affected by group or sex main effect ( $\mathrm{p}>0.05)$. The values of $\mathrm{pH}$ at 45 $\mathrm{min}$ and $24 \mathrm{~h}$ postmortem of the loin muscles were in normal ranges, as they were previously reported to be 6.4 and 5.6 to 5.8 , respectively $[23,24]$. Therefore, the incidence of pale, soft, and exudative (PSE) and dark, firm, and dry (DFD) pork were not found in the present study.

No meat color parameters (CIE L*, $\mathrm{a}^{*}$, and $\mathrm{b}^{*}$ values) were influenced by group $(\mathrm{p}>0.05)$. In agreement with several researchers who reported no effect of breed on $L^{*}, a^{*}$, and $b^{*}$ values of pork loins $[4,22]$. However, LT muscles from barrows were lighter (higher $\left.\mathrm{L}^{*}\right)$ than those of gilts $(\mathrm{p}<0.05)$. This could possibly be due to the difference in muscle fiber type proportion between gilts and barrows. Research has been reported that gilts had higher proportion of type IIb fiber, but lower proportions of type I and IIa fibers than barrows [25]. In ge- 
Table 3. Means \pm standard deviation of meat quality parameters of Longissimus muscle from finished Pakchong 5 pig and crossbred pigs sired by Pakchong 5 or Duroc boar

\begin{tabular}{|c|c|c|c|c|c|c|c|c|}
\hline \multirow{2}{*}{ Items } & \multicolumn{3}{|c|}{ Group (G) } & \multicolumn{2}{|c|}{$\operatorname{Sex}(S)$} & \multicolumn{3}{|c|}{$p$-value } \\
\hline & PP & LWLRP & LWLRD & Gilt & Barrow & G & $S$ & $\mathrm{G} \times \mathrm{S}$ \\
\hline $\mathrm{pH}_{45 \min }$ & $6.13 \pm 0.26$ & $6.19 \pm 0.28$ & $6.34 \pm 0.28$ & $6.25 \pm 0.30$ & $6.18 \pm 0.28$ & 0.08 & 0.39 & 0.34 \\
\hline $\mathrm{pH}_{24 h}$ & $5.75 \pm 1.54$ & $5.71 \pm 0.13$ & $5.76 \pm 0.10$ & $5.76 \pm 1.37$ & $5.71 \pm 0.09$ & 0.58 & 0.12 & 0.67 \\
\hline \multicolumn{9}{|l|}{ Meat color } \\
\hline L* (lightness) & $52.42 \pm 2.47$ & $52.12 \pm 2.74$ & $51.19 \pm 3.18$ & $50.67 \pm 2.40^{y}$ & $53.16 \pm 2.90^{x}$ & 0.39 & $<0.01$ & 0.87 \\
\hline$a^{*}$ (redness) & $3.28 \pm 1.30$ & $3.96 \pm 1.17$ & $3.41 \pm 1.00$ & $3.81 \pm 1.09$ & $3.29 \pm 1.17$ & 0.22 & 0.12 & 0.19 \\
\hline b* (yellowness) & $11.82 \pm 1.07$ & $12.32 \pm 1.09$ & $11.47 \pm 0.81$ & $11.67 \pm 1.07$ & $12.08 \pm 1.01$ & 0.06 & 0.16 & 0.38 \\
\hline \multicolumn{9}{|l|}{ Water holding capacity (\%) } \\
\hline Drip loss & $3.16 \pm 0.72$ & $3.11 \pm 0.67$ & $3.15 \pm 0.78$ & $3.23 \pm 0.83$ & $3.05 \pm 0.58$ & 0.98 & 0.41 & 0.85 \\
\hline Cooking loss & $22.10 \pm 3.25$ & $21.75 \pm 3.08$ & $22.50 \pm 2.53$ & $22.49 \pm 2.84$ & $21.75 \pm 2.77$ & 0.78 & 0.40 & 0.34 \\
\hline Muscle fiber diameter $(\mu \mathrm{m})$ & $71.27 \pm 5.81^{\mathrm{a}}$ & $71.71 \pm 4.27^{\mathrm{a}}$ & $65.70 \pm 6.53^{b}$ & $70.15 \pm 6.91$ & $68.97 \pm 5.40$ & 0.01 & 0.51 & 0.61 \\
\hline Sarcomere length $(\mu \mathrm{m})$ & $1.71 \pm 0.14$ & $1.63 \pm 0.06$ & $1.66 \pm 0.10$ & $1.63 \pm 0.08^{y}$ & $1.70 \pm 0.13^{x}$ & 0.10 & 0.02 & 0.40 \\
\hline Shear force value $(\mathrm{kg})$ & $6.29 \pm 0.69$ & $6.49 \pm 0.79$ & $6.28 \pm 1.19$ & $6.50 \pm 1.00$ & $6.20 \pm 0.82$ & 0.77 & 0.27 & 0.58 \\
\hline
\end{tabular}

1) PP, purebred Pakchong 5; LWLRP, Large White $\times$ Landrace pigs sired by Pakchong 5 boar; LWLRD, Large White $\times$ Landrace pigs sired by Duroc boar. Means within the same row with different superscript letters $\left(^{(a, b}\right)$ under group effect differed at $p<0.05$. Means within the same row with different superscript letters $\left({ }^{x, y}\right)$ under sex effect differed at $p<0.05$.

neral, type IIb fibers are lighter, while type I and IIa fibers are darker and redder [26]. Muscle fiber type I, slow-twitch-oxidative, is small and slow contraction. It has high mitochondria, myoglobin, and lipid contents. Muscle fiber type IIb, fasttwitch-oxidative, is large and fast contraction. It has high glycogen contents [27]. Meta-analysis of gender effects in combination with carcass weight and breed on pork quality found a significant difference among genders for lightness values [8]. They indicated that immunocastrated male pork has the lightest meat color. The same study stated that regarding to pork quality, castrated pigs statistically segregated from the others regardless of type of castration. However, there are controversial in the effect of gender on meat color. Several researchers found no difference in lightness values between genders [4,7].

PP and LWLRP had a larger muscle fiber diameter than LWLRD ( $\mathrm{p}<0.05$, Table 3). Muscle fiber cross-sectional area was also reported to be positively correlated to LEA [28]. This may explain an earlier result of larger LEA found in PP and LWLRP, when compared to that of LWLRD (Table 2). Previous research studied in different pig breeds and reported that myosin heavy chain IIb fibers are the most abundant in pigs having large LEA [29]. The authors suggested that myosin heavy chain IIb fiber is the determining fiber contributing to the differentiation of large and small LEA in the pig. Although, previous study indicated that larger muscle fiber diameter may result in reduced tenderness and WHC of pork loin [30]. We found no differences in WBSF and WHC (drip loss and cooking loss) among groups ( $\mathrm{p}>0.05)$.

There was no significant difference in sarcomere length among groups ( $p>0.05)$. Loin muscles from barrows, however, had longer sarcomere length than those from gilts $(\mathrm{p}<0.05)$. Sarcomere length has been associated with meat tenderness
[13]. But we found no significant difference in WBSF values between sexes $(p>0.05)$. The difference in sarcomere length could be related to the type of muscle fibers dominant in the muscle. Type IIb fibers have been characterized by a shorter sarcomere length than type I fibers [31].

The chemical composition of LT muscles was not affected by group or sex main effect ( $p>0.05$, Table 4 ). Similarly, no influence of crossbreeding or sex was found on chemical composition of pork loins from Duroc $\times$ Large White crossbreds and Pietrain $\times$ Large White crossbreds [7]. Although statistically insignificant, LWLRP had slightly more $(\mathrm{p}>0.05)$ fat content in the loin muscle than LWLRD $(2.11 \%$ and $1.84 \%$, respectively). Intramuscular fat positively influences sensory quality traits of meat including flavor, juiciness, and tenderness [32]. A minimum intramuscular fat content of $2.2 \%$ to $3.4 \%$ was recommended to improve eating acceptability of pork [33]. Furthermore, no influence of group or sex main effect was observed on collagen content of pork loins ( $p>0.05$ ). This is expected as all pigs were slaughtered at the same age. No significant difference on collagen contents among pig breeds with the same age has been reported [34]. Previous study suggested that as an animal ages, the proportion of mature intermolecular crosslinks in collagen molecules increases, resulting in meat toughness [35].

\section{CONCLUSION}

With lighter BW, Pakchong 5 purebred provides good carcass and lean percentages. Comparing to commercial Duroc crossbred pigs, Pakchong 5 crossbred pigs have similar carcass and lean percentages, a larger LEA, and slightly more carcass fat, with similar meat quality and chemical composition. Feed formulation during finishing may be adjusted to accommodate 
Table 4. Means \pm standard deviation of chemical composition and collagen contents of Longissimus muscle from finished Pakchong 5 pig and crossbred pigs sired by Pakchong 5 or Duroc boar

\begin{tabular}{|c|c|c|c|c|c|c|c|c|}
\hline \multirow{2}{*}{ Items } & \multicolumn{3}{|c|}{ Group $(G)^{1)}$} & \multicolumn{2}{|c|}{$\operatorname{Sex}(S)$} & \multicolumn{3}{|c|}{$p$-value } \\
\hline & PP & LWLRP & LWLRD & Gilt & Barrow & G & $S$ & $G \times S$ \\
\hline \multicolumn{9}{|c|}{ Chemical composition (\%) } \\
\hline Moisture & $74.17 \pm 0.74$ & $73.28 \pm 0.85$ & $73.79 \pm 1.21$ & $73.66 \pm 0.97$ & $73.83 \pm 1.04$ & 0.11 & 0.61 & 0.08 \\
\hline Crude protein & $23.17 \pm 1.06$ & $23.83 \pm 1.30$ & $23.58 \pm 1.68$ & $23.72 \pm 1.59$ & $23.33 \pm 1.10$ & 0.55 & 0.44 & 0.22 \\
\hline Crude fat & $1.51 \pm 0.51$ & $2.11 \pm 0.76$ & $1.84 \pm 0.59$ & $1.82 \pm 0.86$ & $1.82 \pm 0.40$ & 0.15 & 0.98 & 0.79 \\
\hline Ash & $1.02 \pm 0.12$ & $1.03 \pm 0.12$ & $1.02 \pm 0.11$ & $1.02 \pm 0.11$ & $1.03 \pm 0.12$ & 0.96 & 0.72 & 0.76 \\
\hline \multicolumn{9}{|c|}{ Collagen contents $(\mathrm{mg} / \mathrm{g})$} \\
\hline Insoluble collagen & $3.68 \pm 1.12$ & $3.36 \pm 0.65$ & $3.46 \pm 1.16$ & $3.47 \pm 0.90$ & $3.54 \pm 1.09$ & 0.76 & 0.84 & 0.14 \\
\hline Soluble collagen & $0.54 \pm 0.15$ & $0.59 \pm 0.14$ & $0.49 \pm 0.19$ & $0.54 \pm 0.15$ & $0.54 \pm 0.18$ & 0.28 & 0.94 & 0.06 \\
\hline Total collagen & $4.23 \pm 1.24$ & $3.96 \pm 0.77$ & $3.94 \pm 1.34$ & $4.00 \pm 1.03$ & $4.08 \pm 1.22$ & 0.82 & 0.84 & 0.13 \\
\hline
\end{tabular}

1) PP, purebred Pakchong 5; LWLRP, Large White $\times$ Landrace pigs sired by Pakchong 5 boar; LWLRD, Large White $\times$ Landrace pigs sired by Duroc boar.

appropriate fat deposition. Gilts have more loin percentage and darker loin color than barrows, which might be due to muscle fiber type proportion variation. Since developed by governmental agency, Pakchong 5 terminal boars are more affordable for very small- to medium-scale pig producers. The sensory quality and consumer acceptance of meat from Pakchong 5 crossbred pigs are to be further investigated.

\section{CONFLICT OF INTEREST}

We certify that there is no conflict of interest with any financial organization regarding the material discussed in the manuscript.

\section{ACKNOWLEDGMENTS}

This study was granted by the Thailand Research Fund (TRF). Research facilities were supported by the DLD Thailand, the Meat Technology Research Network Center, Department of Animal Production Technology and Fisheries, Faculty of Agricultural Technology, KMITL, and Department of Agricultural Education, Faculty of Industrial Education and Technology, KMITL. The authors would like to thank Assoc. Prof. Dr. Panneepa Sivapirunthep for all suggestion.

\section{REFERENCES}

1. Office of Agricultural Economics. Major agricultural products and trends in 2016 [Internet]. Thailand Ministry of Agriculture and Cooperatives; 2017 [cited $2017 \mathrm{Feb} 2$ ]. Available from: http://oldweb.oae.go.th/download/document_tendency/agri_ situation2560.pdf

2. Latorre MA, Medel P, Fuentetaja A, Lázaro R, Mateos GG. Effect of gender, terminal sire line and age at slaughter on performance, carcass characteristics and meat quality of heavy pigs. Anim Sci 2003;77:33-45.

3. Miar Y, Plastow GS, Moore SS, et al. Genetic and phenotypic parameters for carcass and meat quality traits in commercial crossbred pigs. J Anim Sci 2014;92:2869-84.

4. Alonso V, Campo Mdel M, Espanol S, Roncales P, Beltran JA. Effect of crossbreeding and gender on meat quality and fatty acid composition in pork. Meat Sci 2009;81:209-17.

5. Suzuki K, Shibata T, Kadowaki H, Abe H, Toyoshima T. Meat quality comparison of Berkshire, Duroc and crossbred pigs sired by Berkshire and Duroc. Meat Sci 2003;64:35-42.

6. Bunter KL, Bennett C, Luxford BG, Graser HU. Sire breed comparisons for meat and eating quality traits in Australian pig populations. Animal 2008;2:1168-77.

7. Latorre MA, Lazaro R, Gracia MI, Nieto M, Mateos GG. Effect of sex and terminal sire genotype on performance, carcass characteristics, and meat quality of pigs slaughtered at $117 \mathrm{~kg}$ body weight. Meat Sci 2003;64:1369-77.

8. Trefan L, Doeschl-Wilson A, Rooke JA, Terlouw C, Bunger L. Meta-analysis of effects of gender in combination with carcass weight and breed on pork quality. J Anim Sci 2013;91:1480-92.

9. Chaweewan K, Nakavisut S, Jumparat V, Srisuriya V. Genetic parameters of selection for economic traits over five generations of Pakchong 5 swine. In: Proceeding of the 15th AAAP Animal Science Congress 2012; 2012 Nov 26-30; Thammasat University, Rangsit Campus, Thailand.

10. Information and Communication Technology Center. Statistics of livestock in Thailand 2015 [Internet]. Department of Livestock Development, Thailand; 2015 [cited 2016 Dec 4]. Available from: http://ict.dld.go.th/th2/images/stories/stat_web/yearly/ 2558/province/4.buffpig_province.pdf

11. Honikel KO. Reference methods for the assessment of physical characteristics of meat. Meat Sci 1998;49:447-57.

12. Tuma HJ, Venable JH, Wuthier PR, Henrickson RL. Relationship of fiber diameter to tenderness and meatiness as influenced by Bovine age. J Anim Sci 1962;21:33-6.

13. Wheeler TL, Shackelford SD, Koohmaraie M. Technical note: Sampling methodology for relating sarcomere length, collagen concentration, and the extent of postmortem proteolysis to beef and pork longissimus tenderness. J Anim Sci 2002;80:982- 
7.

14. AOAC. Official methods of analysis (17th ed). Gaithersburg, MD, USA: AOAC International; 2000.

15. Hill F. The solubility of intramuscular collagen in meat animals of various ages. J Food Sci 1966;31:161-6.

16.SPSS. Statistical Package for the Social Sciences. In: 17.0 version. Chicago, IL, USA: SPSS Inc.; 2008.

17. Cassady JP, Young LD, Leymaster KA. Heterosis and recombination effects on pig growth and carcass traits. J Anim Sci 2002;80:2286-302.

18. Edwards DB, Tempelman RJ, Bates RO. Evaluation of Durocvs. Pietrain-sired pigs for growth and composition. J Anim Sci 2006;84:266-75.

19. Edwards DB, Bates RO, Osburn WN. Evaluation of Duroc- vs. Pietrain-sired pigs for carcass and meat quality measures. J Anim Sci 2003;81:1895-9.

20. Morales JI, Serrano MP, Camara L, et al. Growth performance and carcass quality of immunocastrated and surgically castrated pigs from crossbreds from Duroc and Pietrain sires. J Anim Sci 2013;91:3955-64.

21.Dube B, Mulugeta SD, Dzama K. Genetic relationship between growth and carcass traits in Large White pigs. S Afr J Anim Sci 2013;43:482-92.

22. McCann MEE, Beattie VE, Watt D, Moss BW. The effect of boar breed type on reproduction, production performance and carcass and meat quality in pigs. Irish J Agric Food Res 2008; 47:171-85.

23. Faucitano L, Ielo MC, Ster C, et al. Shelf life of pork from five different quality classes. Meat Sci 2010;84:466-9.

24. Warriss PD, Brown SN. The relationships between initial pH, reflectance and exudation in pig muscle. Meat Sci 1987;20:6574.

25. Okrouhlá M, Č́tek J, Stupka R, Brzobohatý L, Mahcová M. The effect of gender on the characteristics of muscle fibers in pork. J Cen Eur Agric 2014;15:64-71.

26. Picard B, Lefaucheur L, Berri C, Duclos MJ. Muscle fibre ontogenesis in farm animal species. Reprod Nutr Dev 2002;42:41531.

27. Aberle ED, Forrest JC, Gerrard DE, Mills EW. Principles of meat science. Kendall Hunt Publishing; 2012.

28. Ryu YC, Rhee MS, Kim BC. Estimation of correlation coefficients between histological parameters and carcass traits of pig longissimus dorsi muscle. Asian-Australas J Anim Sci 2004;17: 428-33.

29. Wimmers K, Ngu NT, Jennen DG, et al. Relationship between myosin heavy chain isoform expression and muscling in several diverse pig breeds. J Anim Sci 2008;86:795-803.

30. Bulotienè G, Jukna V. The influence of muscle fibre area on pork quality. Vet Med Zoot 2008;42:34-7.

31. Christensen M, Kok C, Ertbjerg P. Mechanical properties of type I and type IIB single porcine muscle fibres. Meat Sci 2006; 73:422-5.

32. Frank D, Joo ST, Warner R. Consumer acceptability of intramuscular fat. Korean J Food Sci Anim Resour 2016;36:699708.

33. Font-i-Furnols M, Tous N, Esteve-Garcia E, Gispert M. Do all the consumers accept marbling in the same way? The relationship between eating and visual acceptability of pork with different intramuscular fat content. Meat Sci 2012;91:448-53.

34. Glinoubol J, Jaturasitha S, Mahinchaib P, Wicke M, Kreuzer M. Effects of crossbreeding Thai native or Duroc pigs with Pietrain pigs on carcass and meat quality. Agric Agric Sci Procedia 2015; 5:133-8.

35. Weston RA, Rogers WR, Althen GT. Review: the role of collagen in meat tenderness. Prof Anim Sci 2002;18:107-11. 